\title{
Spinal glioblastoma with brain relapse in a child: clinical considerations
}

\author{
E Caroli*,1, M Salvati ${ }^{2}$ and L Ferrante ${ }^{1}$ \\ ${ }^{1}$ Department of Neurological Sciences, Neurosurgery-Ospedale S. Andrea-University of Rome 'La Sapienza', Rome, \\ Italy; ${ }^{2}$ Department of Neurosurgery, INM Neuromed IRCCS, Pozzilli (Is), Italy
}

\begin{abstract}
Study design: Case report.
Objectives: To describe a child with intramedullary glioblastoma at $\mathrm{T}_{9}-\mathrm{T}_{10}-\mathrm{T}_{11}$, and to discuss the clinical features of this rare pathology.

Setting: Department of Neurological Sciences, Italy.

Case report: Spinal cord glioblastoma in children has only rarely been reported. It most frequently involves the thoracic region with a predilection for the second and third decades of life. This report describes one case of thoracic glioblastoma multiforme in a 6-year-old child and reviews other cases reported in the literature.

Results: Laminectomy and excision of the tumour were performed. Postoperative radiotherapy and chemotherapy were given, but 4 months later the patient presented with a brain relapse of the tumour. At 9 months after diagnosis the patient died from cerebral tumour regrowth.
\end{abstract}

Conclusions: Full neuraxis MRI is always recommended in order to detect possible metastases. The prognosis after multimodality therapy (surgery, radiotherapy, chemotherapy) remains poor. From the literature, only four cases of paediatric patients with long-term survival have been reported.

Spinal Cord (2005) 43, 565-567. doi:10.1038/sj.sc.3101749; published online 19 April 2005

Keywords: children; glioblastoma; intramedullary; radiotherapy; spinal cord tumour; surgery

\section{Introduction}

Primary spinal cord tumours in children are rare. In patients under 15 years of age, the ratio of brain to spinal cord tumours ranges from 8:1 to $22: 1$. $^{1,2}$ Most intramedullary tumours in children are astrocytomas (47-88\%) followed by ependymomas $(24-37 \%),{ }^{1-5}$ other tumours are uncommon. In particular, intramedullary glioblastomas are rarely described. These tumours occur mainly in the cervico-thoracic segments and have a short clinical history before diagnosis. ${ }^{6}$ The aim of this paper is to report one case of a 6-year-old boy with intramedullary glioblastoma that spread to brain and to discuss the clinical, radiologic and therapeutic findings of these tumours with a review of the pertinent literature.

\section{Case report}

A 6-year-old boy presented with a 4-month history of increasing weakness of the lower limbs. Neurological examination disclosed severe spastic paraparesis and hypoaestesia to touch, temperature and pain with an upper border at $\mathrm{T}_{10}$. A magnetic resonance imaging scan of the spinal cord revealed an intramedullary expanding

*Correspondence: E Caroli, Via Meropia 85, 00147 Rome, Italy lesion (Figure 1a) with contrast enhancement (Figure 1b) from $T_{9}$ to $T_{11}$. Full neuraxis magnetic resonance imaging (MRI) revealed no other lesions. Surgery disclosed an intramedullary invasive necrotic tumour extending from $T_{9}$ to $T_{11}$; subtotal removal of the lesion and dural decompression were performed. The histological examination of the excised tumour revealed a glioblastoma multiforme. The patient's postoperative course was uneventful. The patient received radiotherapy $(40 \mathrm{~Gy}$ to the entire spinal axis with LINAC) and chemotherapy (PCV). After 4 months, he was admitted to our institution for headache and vomiting. A brain MRI showed a ring enhancing mass in the left frontal lobe (Figure 2a, b). An MRI showed no other intramedullary lesions. The patient underwent a craniotomy. The tumor was subtotally removed (Figure 2c). The histological examination was consistent with a glioblastoma multiforme. The patient died 9 months later from cerebral tumor regrowth.

\section{Discussion}

Spinal cord tumours in children are quite rare. They represent approximately $4 \%$ of childhood central 
nervous system tumours. ${ }^{1,4}$ The majority are astrocytomas (47-88\%), followed by ependymomas $(27-37 \%)$. Intramedullary glioblastoma is uncommon in all ages of life, but in children are extremely rare. ${ }^{6-8}$

Intramedullary glioblastoma shows a slight predilection for the second and third decades of life, the mean age ranging from 28.5 years in the 20 -case series of the Mayo Clinic $^{9}$ to 18.1 years according to the review of the literature undertaken by Fortuna in $1971 .{ }^{10}$ Our patient was a 6-year-old. The clinical presentation of our case was very rapid, with a duration of symptoms of only 4 months. This is consistent with previous studies of malignant spinal tumours. ${ }^{6,11}$ Spinal cord glioblastomas occur mainly in the cervical or thoracic segments. ${ }^{9,10,12-19}$ In our case glioblastoma was localised at $\mathrm{T}_{9}-\mathrm{T}_{11}$. Spinal cord glioblastoma shows a tendency to spread via the subarachnoid space at the spinal and, more rarely, at the brain level. ${ }^{6,13,20,21}$ This can be
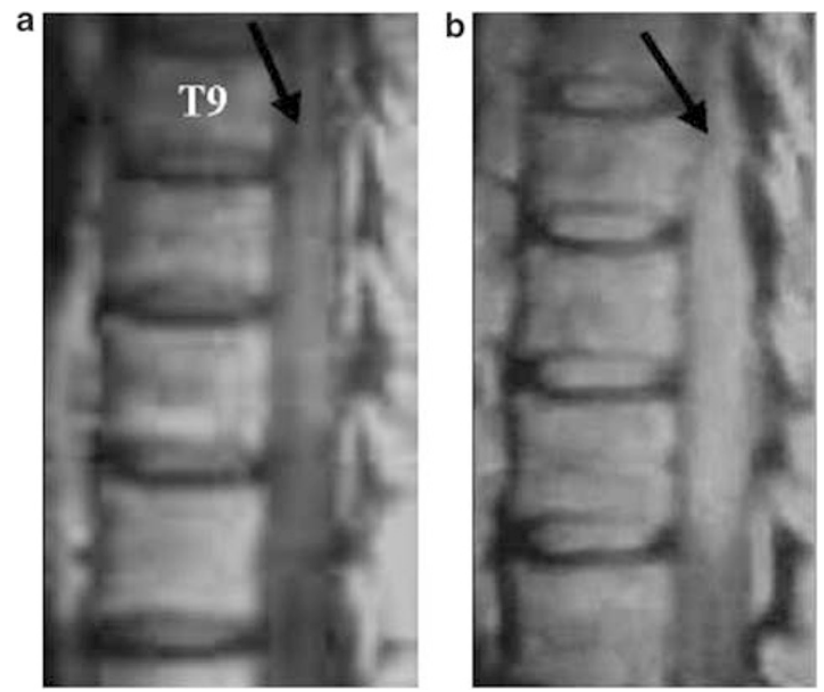

Figure 1 Sagittal $\mathrm{T}_{1}$-weighted MRI without gadolinium (a) and with gadolinium (b) showing the enhancing spinal cord tumour (arrow) explained by the proximity of the neoplastic cells to the cerebrospinal fluid pathways. ${ }^{6,13,14}$ However, the possibility of surgical dissemination of glioblastoma through increased exposure of the subarachnoid spaces to the malignant glial cells cannot be excluded. ${ }^{6,13}$ Also, the presence of multiple foci should be considered. $6,10,13,14$ Seeding of a spinal cord glioblastoma to the brain is extremely rare. ${ }^{6,13,20}$ In our case, a cerebral relapse occurred 4 months after the diagnosis of a spinal tumour. In the similar cases reported in the literature, the interval between the onset of spinal cord symptoms and the onset of intracranial symptoms varied from 1 week to 1 year. $6,18,21-23$

MRI is the diagnostic procedure of choice for spinal tumours. $^{24}$ In the presented case, MRI was able to accurately define the tumour extending from $T_{9}$ to $T_{11}$. Full neuraxis MRI is always recommended in order to detect possible metastases.

As these tumors are rare, reliable information on therapy and prognosis is limited. The role of surgery in the management of intramedullary tumours of the spinal cord has been expanded in recent years. Until recently, surgical management of an intramedullary mass consisted of biopsy, or cyst aspiration with decompressive laminectomy. ${ }^{25,26}$ Recent advances in imaging and microsurgical technique have established microsurgical removal as the single most effective treatment for benign intramedullary tumours. ${ }^{2,4,26}$ Surgical removal in patients with intramedullary glioblastoma cannot be radical because there is not a clear cleavage plane between the glioblastoma and the medullary parenchyma. However, surgery should be 'reasonably aggressive' so that the tumour bulk is reduced for radiation therapy. Our patient had no adverse sequelae from the subtotal resection of its tumour. Because of the high incidence of postoperative spinal deformities following laminectomy in paediatric patients, laminoplasty should be performed in spinal surgery. ${ }^{2,26-28}$ However, the onset of deformity ranges from 8 months to 7.5 years. Intramedullary glioblastoma is a fatal disease with so short survival time that iatrogenic spinal deformity does not occur. Dural decompression may be an advisable procedure.
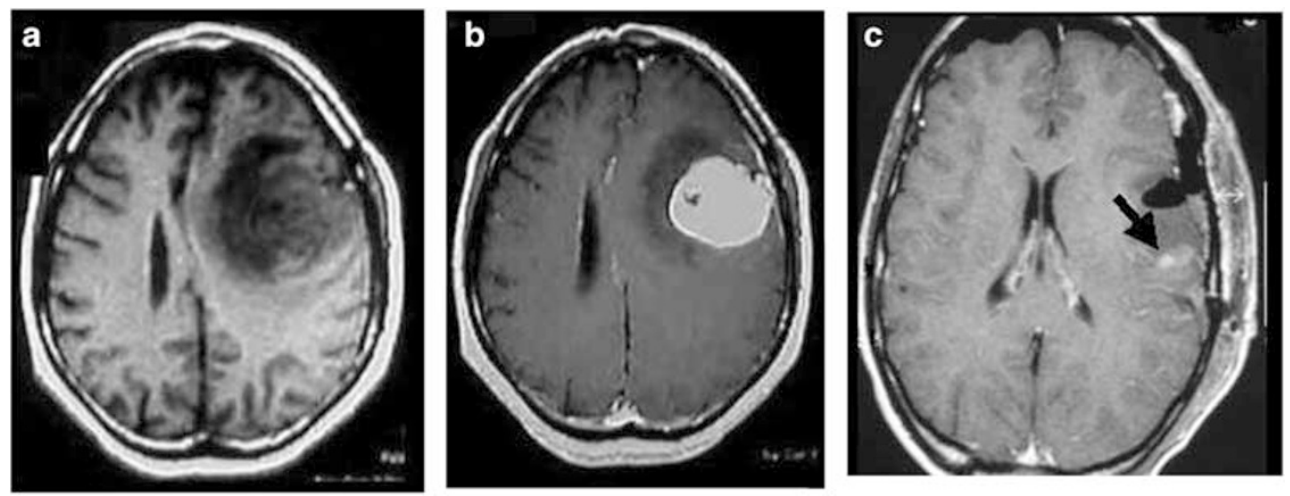

Figure 2 Axial $\mathrm{T}_{1}$-weighted MRI without gadolinium (a) and with gadolinium (b) showing an enhancing left frontal lesion. Immediate postoperative MRI shows a small tumour residue (c, arrow) 
The value of radiotherapy in spinal cord malignant

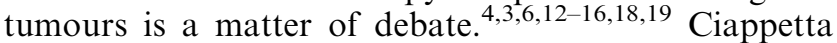
et $a l^{6}$ in their series of six adult patients and one paediatric patient reported a beneficial effect of radiotherapy. Moreover, one should take into account that survival time is so short that the late effects of radiotherapy will never be observed. Only four series of paediatric patients with spinal cord glioblastoma have reported long-term survivors. ${ }^{12,15,18,24,29}$ These cases represent an exception. Prognosis in patients with spinal cord glioblastomas remains poor. The value of chemotherapy is unknown. In our patient, we have performed a multimodality therapy (surgery, radiotherapy and chemotherapy) as for the intracranial glioblastomas, observing a survival time of 9 months.

\section{References}

1 Farwell JR, Dohrmann GJ, Flamery JT. Central nervous system tumors in children. Cancer 1977; 40: 3123-3132.

2 Reimer R, Onofrio BM. Astrocytomas of the spinal cord in children and adolescents. J Neurosurg 1985; 63: 669-675.

3 Cooper PR, Epstein F. Radical resection of intramedullary spinal cord tumor in adults. J Neurosurg 1985; 63: 491-492.

4 Epstein F, Epstein N. Intramedullary tumors of the spinal cord. In: Section of Pediatric Neurosurgery of the American Association of Neurological Surgeons (eds). Pediatric Neurosurgery. Surgery of the Developing Nervous System. Grim \& Straton: New York 1982, pp 529-533.

5 Garret PG, Simpson WJK. Ependymomas: results of radiation treatment. Int $J$ Radiat Oncol Biol Phys 1983; 9: 1121-1124.

6 Ciappetta P, Maurizio S, Capoccia G, Artico M, Raco A, Fortuna A. Spinal glioblastoma: report of seven cases and review of the literature. Neurosurgery 1981; 28: 302-306.

7 O'Sullivan C, Jenkin RD, Doherty MA, Hoffman HJ, Greenberg ML. Spinal cord tumors in children: long-term results of combined surgical and radiation treatment. J Neurosurg 1994; 81: 507-512.

8 Nadkarni TD, Rekate HL. Paediatric intramedullary spinal cord tumors. Critical review of the literature. Child's Nerv Syst 1999; 15: 17-28.

9 Russel DS, Rubinstein LJ. Pathology of Tumors of the Nervous System. Edward Arnold: London 1989, pp 219-247.

10 Fortuna A, Giuffrè R. Intramedullary glioblastoma. Neurochirurgia (Stuttg) 1971; 14: 14-23.

11 Bouffet E, Pierre-Kahn A. Prognostic factors in pediatric spinal cord astrocytoma. Cancer 1998; 83: 2391-2399.
12 Alvisi C, Cerisoli M, Giuliani M. Intramedullary spinal gliomas: long term results of surgical treatment. Acta Neurochir (Wien) 1984; 70: 169-179.

13 Cohen AR, Wisoff JH, Allen JC, Epstein F. Malignant astrocytomas of the spinal cord. J Neurosurg 1989; 70: $50-54$.

14 Grisold W, Pernetzky G, Jellinger K. Giant cell glioblastoma of the thoracic cord. Acta Neurochir (Wien) 1981; 58: $121-126$.

15 Guidetti B, Mercuri S, Vagnozzi R. Long-term results of the surgical treament of 129 intramedullary spinal gliomas. J Neurosurg 1981; 54: 323-330.

16 Guidetti B, Fortuna A, Moscatelli G, Riccio A. I tumori intramudollari. Lav Neuropsichiatr 1964; 35: 409.

17 Helseth A, Mork SJ. Primary intraspinal neoplasms in Norway, 1955 to 1986 . A population-based survey of 467 patients. J Neurosurg 1989; 71: 84-85.

18 Kopelson G, Lingood RM. Intramedullary spinal cord astrocytoma versus glioblatomas. The prognostic importance of histologic grade. Cancer 1982; 50: 732-735.

19 Malis LI. Intramedullary spinal cord tumors. Clin Neurosurg 1978; 25: 512-539.

20 Bell WO et al. Leptomeningeal spread of intramedullary spinal cord tumors. Report of three cases. J Neurosurg 1988; 69: 295-300.

21 Andrews AA, Enriques L, Renaudin J, Tomiyasu V. Spinal intramedullary glioblastoma with intracranial seeding. Arch Neurol 1978; 35: 244-245.

22 Johnson DL, Schwarz S. Intracranial metastasis from malignant spinal cord astrocytoma. J Neurosurg 1978; 66: 621-625.

23 Eade OE, Urich H. Metastasizing gliomas in young subjects. J Pathol 1971; 103: 245-256.

24 Kulkarni A, Armstrong DC, Drake JM. MR characteristics of malignant spinal cord astrocytomas in children. Can J Neurol Sci 1999; 26: 290-293.

25 Woltman HW et al. Intramedullary tumors of the spinal cord and gliomas of intradural portion of filum terminale: fate of patients who have these tumors. Arch Neurol Psychiatry 1951; 65: 378-393.

26 Kaufman BA, Park TS. Congenital spinal cord astrocytomas. Child's Nerv Syst 1992; 8: 389-393.

27 Gutierrez FA, Oi S, McLone DG. Intraspinal tumors in children: clinical review, surgical results and follow-up in 51 cases. Concepts Pediatr Neurosurg 1983; 4: 291-305.

28 Vles JSH, Grubben CPM, van Ooy A, Weil EHJ. Holocord astrocytomas in childhood. Clin Neurol Neurosurg 1990; 9: 361-364.

29 Przybylski GJ, Albright AL, Martinez AJ. Spinal cord astrocytoma: long-term results comparing treatments in children. Child's Nerv Syst 1997; 13: 375-382. 